\title{
META ANALYSIS THE EFFECT OF TYPE 2 DIABETES MELLITUS ON COVID-19 MORTALITY
}

\author{
Oktaviana Kurniawati'), Hanung Prasetya²), Bhisma Murti') \\ 1)Masters Program in Public Health, Universitas Sebelas Maret \\ ${ }^{2)}$ Health Polytechnics, Ministry of Health Surakarta
}

\begin{abstract}
Background: People with type 2 diabetes are known more susceptible to infections and require longer hospitalization. It resulted in an overall worse prognosis. As the COVID-19 pandemic has progressed, a similar pattern of a worse prognosis for people with diabetes who contract COVID-19 has been reported in population-based studies, with an increased risk of intensive care admission and worse mortality outcome. This study aimed to describe the relationship between type 2 diabetes mellitus on COVID-19 mortality.

Subjects and Method: This was a systematic review and meta analysis. Articles published from 2020 to 2021 in PubMed, Google Scholar, JAMA, Willey, and Science Direct databases were collected by PRISMA guideline. Keywords used (Type 2 diabetes mellitus OR diabetic) AND (mortality OR death) AND (COVID-19 /OR Coronavirus OR SARS-CoV-2) AND ("adjusted odds ratio" OR "aOR". The inclusion criteria were full text in English language and observational studies. Selected articles were assessed using Review Manager (RevMan 5.3).

Results: 6 cohort studies were included for meta-analysis. This study showed that people with type 2 DM comorbidity had possibility 1.93 times to death caused by COVID-19 than those without type $2 \mathrm{DM}(\mathrm{aOR}=1.93 ; 95 \% \mathrm{CI}=1.28$ to $2.90 ; \mathrm{p}=0.002)$. Conclusion: Type 2 DM comorbidity increases the risk of COVID-19 mortality.
\end{abstract}

Keywords: type 2 diabetes mellitus, COVID-19, mortality

\section{Correspondence:}

Oktaviana Kurniawati. Masters Program in Public Health, Universitas Sebelas Maret. Jl. Ir. Sutami 36A, Surakarta 57126, Central Java. Email: oktaniawati94@gmail.com. Mobile: 085865463742. 